\title{
An asymptomatic male with coexisting celiac disease and primary biliary cirrhosis
}

\author{
FranZJOSEF SCHWEIGER, BSC, MD, FRCPC, FACG, JASIM RADHI, MB, MRC(PATH), FRCPC
}

F SCHWEIGER, J RADHI. An asymptomatic male with coexisting celiac disease and primary biliary cirrhosis. Can J Gastroenterol 1991;5(5):179-183. Both primary biliary cirrhosis and celiac disease may be asymptomatic in many patients for extended periods of time. Rarely the disorders have been reported to occur together, in which case symptomatic malabsorption and diarrhea are virtually always present. An unusual case is presented of an asymptomatic male patient who had both primary biliary cirrhosis and celiac disease. The literature describing this coexistence, and theories regarding a common etiological link between the two disorders, are reviewed.

Key Words: Celiac disease, Malabsorption, Primary biliary cirrhosis

\section{Patient asymptomatique porteur d'une maladie coeliaque et} d'une cirrhose biliaire primaire

RESUME: La cirrhose biliaire primaire et la maladie coeliaque peuvent être toutes deux asymptomatiques chez de nombreux patients et sur de longues périodes. Mais, d'après les rapports, ces deux affections se manifestent rarement ensemble - auquel cas une malabsorption et une diarrhée symptomatiques sont virtuellement toujours présentes. On rapporte le cas inhabituel d'un patient asymptomatique, porteurs des deux maladies; on examine la littérature faisant état de cette coexistence et des théories relatives au lien étiologique qui existerait entre les deux affections.

The Moncton Hospital, Moncton, New Brunswick

Correspondence and reprints: Dr F Schweiger, 100 Arden Street, Suite 405, Moncton,

New Brunswick E1C 4B7. Telephone (506) 858-8441

Received for publication July 12, 1991. Accepted September 13, 1991
A NUMBER OF AUTOIMMUNE DISeases have been reported in association with primary biliary cirrhosis, and in the presence of diarrhea and malabsorption, concomitant celiac disease should be considered in the differential diagnosis (1).

An unusual case is described of a 51-year-old male who was found to have both primary biliary cirrhosis and celiac disease, in the absence of symptoms.

\section{CASE PRESENTATION}

A 51-year-old male was referred in January 1989 because of an elevated serum alkaline phosphatase. He had been originally investigated in December 1987 for transient chest pain after lifting heavy objects. Cardiac evaluation was negative but the serum alkaline phosphatase was $1039 \mathrm{U} / \mathrm{L}$ (normal 41 to 133 ). Bone scan was normal. Repeat serum alkaline phosphatase six months later was $1080 \mathrm{U} / \mathrm{L}$, with the hepatic isoenzyme fraction elevated. 


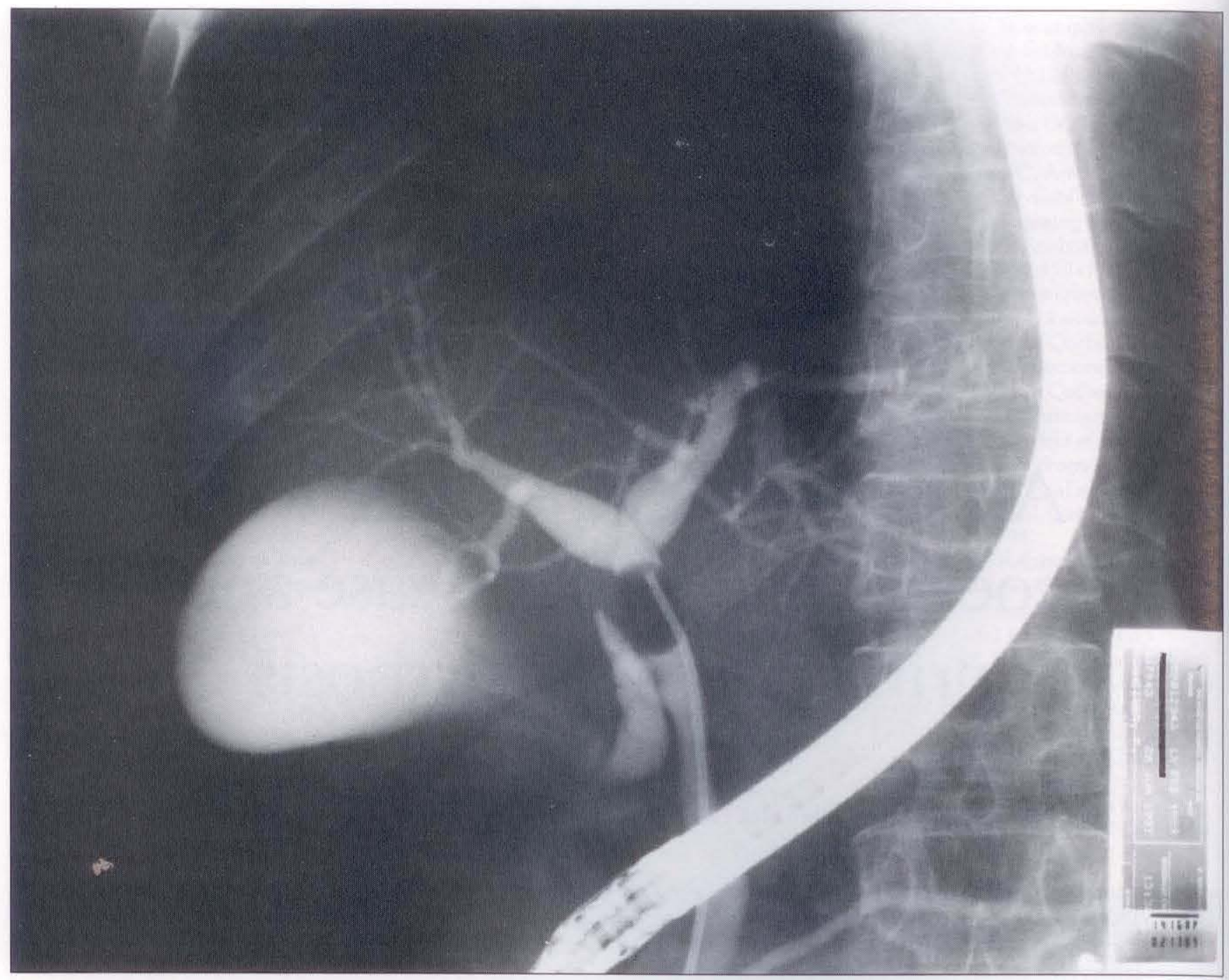

Figure 1) Retrograde cholangiogram demonstrating a normal intrahepatic biliary tree. A balloon catheter is placed above the cystic duct insertion to obtain optimal filling

The patient had been previously well except for a tonsillectomy and rheumatic fever at the age of nine years. He gave no history of alcohol or drug use. He never travelled outside Canada and denied weight loss, abdominal pain, diarrhea, gastrointestinal bleeding or a prior history of jaundice or anemia. There was no history of pruritus and the patient had no specific complaint. He denied any family history of gastrointestinal or hepatobiliary diseases.

Physical examination was completely normal and the patient lacked stigmata of chronic liver disease. Hemoglobin was $104 \mathrm{~g} / \mathrm{L}$ (normal 117 to 166 ) with a hypochromic microcytic blood film showing numerous target cells. The white blood cell and platelet counts were normal. Serum iron studies and ferritin level confirmed the presence of iron deficiency. Serum alkaline phosphatase was $1195 \mathrm{U} / \mathrm{L}$, gamma-glutamyltransferase $733 \mathrm{U} / \mathrm{L}$ (normal 9 to 76 ) and aspartate aminotransferase $112 \mathrm{U} / \mathrm{L}$ (normal 8 to 40 ).

Ultrasound of the abdomen and a liver-spleen scan were normal. An air contrast barium enema suggested a cecal filling defect, but colonoscopy ruled out any colonic lesion. Endoscopic retrograde cholangiopancreatography was completely normal and, in particular, the intrahepatic biliary tree was well visualized and free from any abnormality (Figure 1). However, the duodenal mucosa looked atrophic with loss of Kerckring's folds. Two small bowel biopsies taken from the third part of the duodenum confirmed the presence of total villous atrophy (Figure 2). Further malabsorption workup revealed an abnormal D-xylose test and reduced serum and red cell folate levels. Serum $B_{12}$, calcium, albumin, partial throm. boplastin and prothrombin time were normal.

An upper gastrointestinal series and small bowel follow-through showed prolonged transit and mild flocculation of barium; there was also mild dilation of small bowel loops. Hepatitis B serol. ogy, antismooth muscle and antinuclear antibody titres were negative. The antimitochondrial antibody was present at a titre of greater than 1:640. A percutaneous liver biopsy showed ex. pansion of portal tracts with replacement of the bile ductules by a 


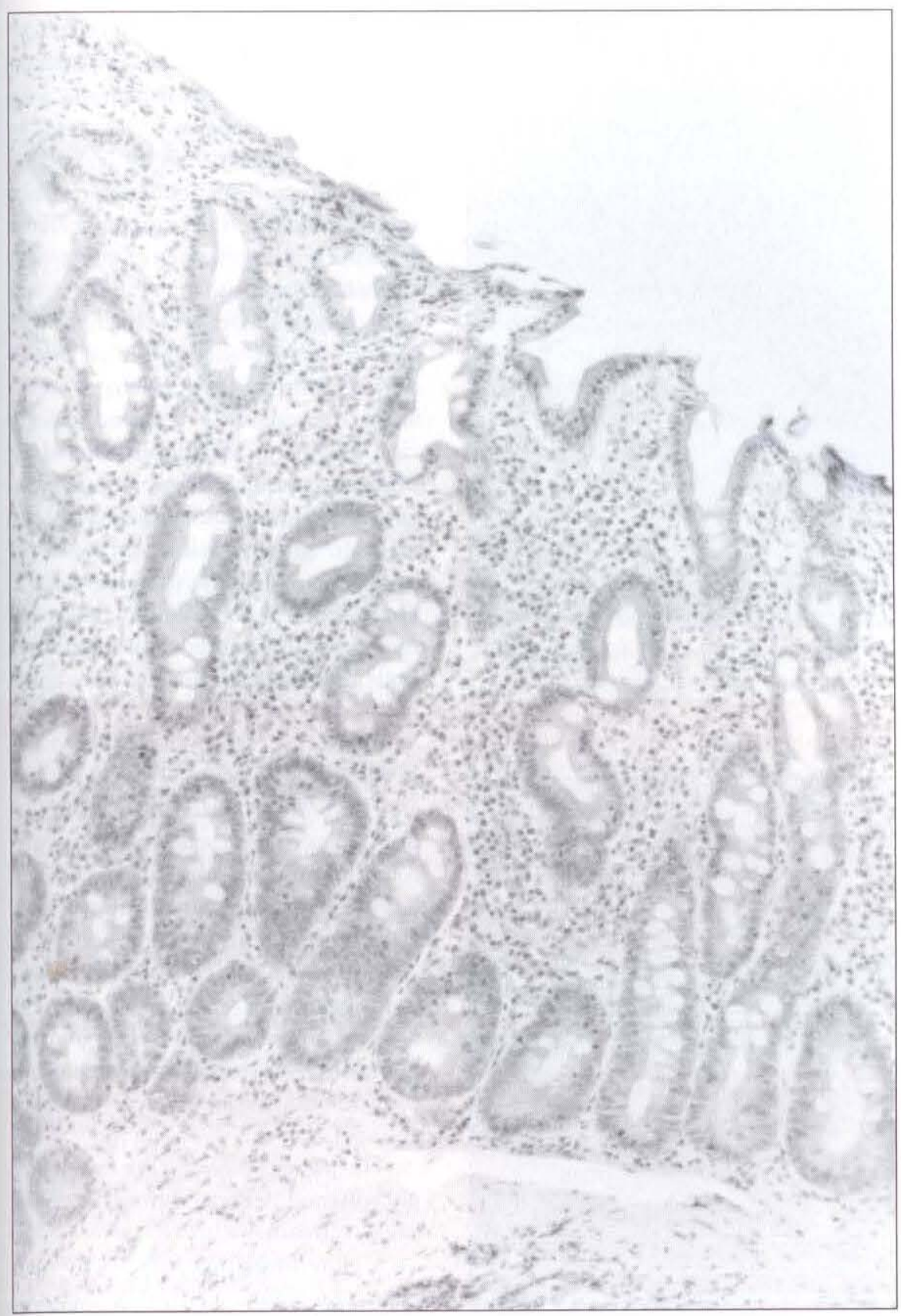

Figure 2) Duodenal biopsy showing subtotal villous atrophy and crypt hyperplasia associated with a marked increase in cellularity of the lamina propria, consisting mainly of plasma cells and lymphocytes (hematoxylin and eosin $\times 65$ )

lymphocytic aggregate (Figure 3) and focal piecemeal necrosis in some portal triads. The patient was placed on a strict gluten-free diet and was given a three month course of oral iron and folic acid therapy.

Within a few weeks the patient reported significant improvement of energy, general well-being and weight gain, despite not having had any earlier complaints.

Re-evaluation six months later in- mitochondrial antibody titre was again greater than 1:640. His human lymphocyte antigen (HLA) haplotype was determined to be HLA-A1, B8, DR3.

A repeat liver enzyme profile in October 1990 showed a persistently elevated alkaline phosphatase of 762 $\mathrm{U} / \mathrm{L}$, an aspartate aminotransferase of $155 \mathrm{U} / \mathrm{L}$ and normal serum bilirubin levels.

At present, the patient continues to feel well on a gluten-free diet.

\section{DISCUSSION}

Celiac sprue is characterized by a structurally abnormal small intestinal mucosa leading to malabsorption which improves while the patient is on a gluten-free diet. Re-introduction of dietary gluten usually leads to clinical and histological relapse. The reported patient had evidence of malabsorption caused by inflamed atrophic small bowel mucosa. The clinical improvement and weight gain, the correction of iron and folate deficiencies, and the marked improvement in small intestinal biopsy after the institution of a gluten-free diet, all support the diagnosis of celiac disease in this patient.

Various liver diseases have been described in conjunction with celiac disease (2): the spectrum ranges from hepatic steatosis (3) and 'nonspecific' hepatitis to chronic active hepatitis and cirrhosis (4). In a retrospective analysis of 74 celiac patients, Hagender et al (2) documented histological evidence of liver injury in $16 \%$ and abnormal liver function tests in $39 \%$, indicating that hepatic injury is not rare in adult celiac disease. More recently there has been a report of three celiac patients affected by primary sclerosing cholangitis (5).

Primary biliary cirrhosis, another autoimmune disorder characterized by a distinct histological picture - biochemical evidence of cholestasis in the presence of a normal biliary tree and the finding of antimitochondrial antibodies - has previously been described in patients with celiac disease (6). Up to the present time fewer than 20 fully documented cases of coexisting primary biliary cirrhosis and celiac disease have 


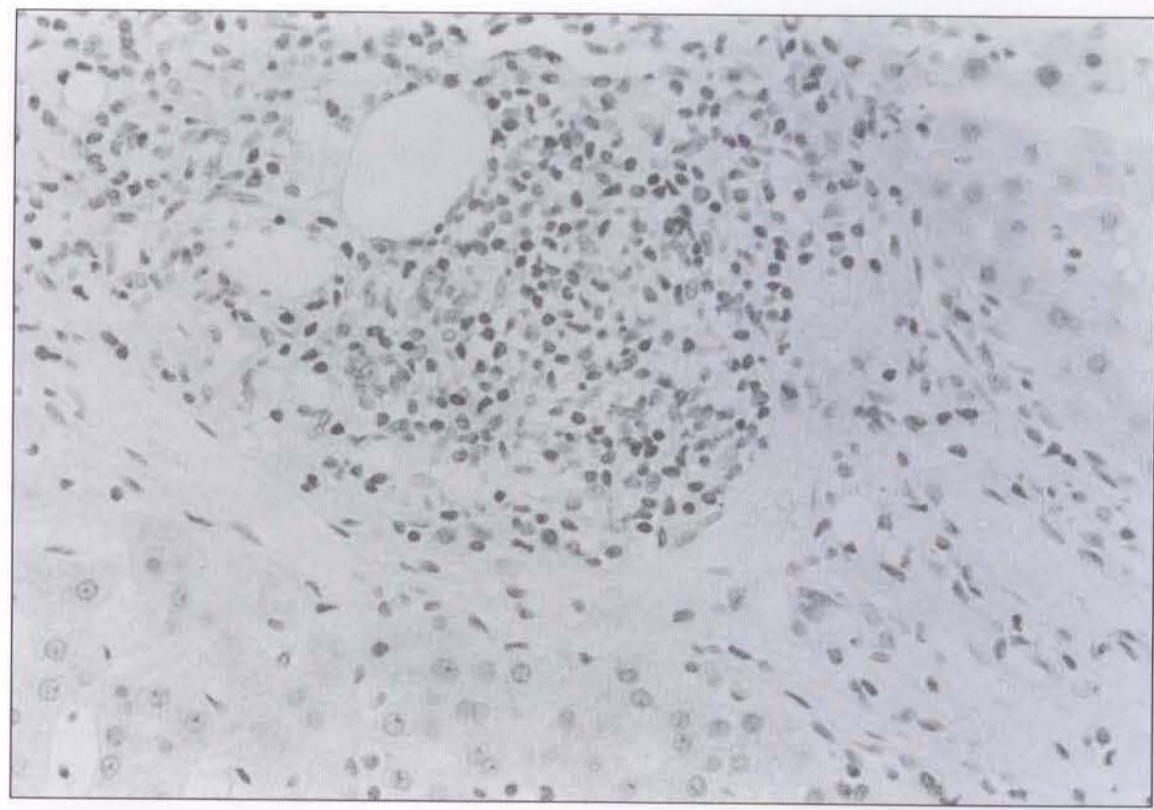

Figure 3) Liver biopsy showing expansion of a portal triad and replacement of bile ductules by a lymphocytic aggregate (hematoxylin and eosin $\times 160$ )

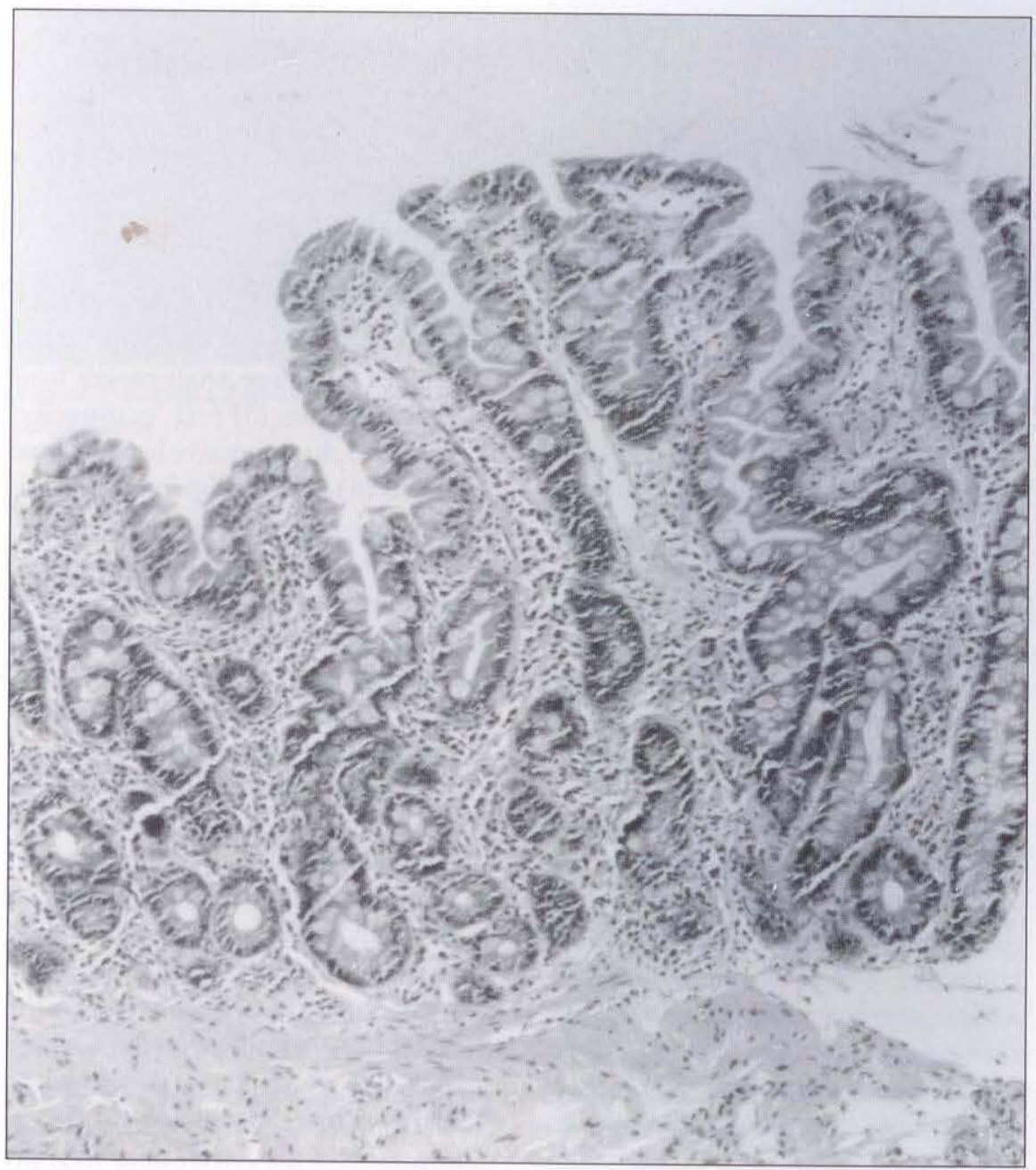

Figure 4) Duodenal biopsy showing restoration of the villous architecture with lack of inflammation and crypt hyperplasia (hematoxylin and eosin $\times 65$ ) appeared in the literature (7-18). Although the majority of these patients were female, the present patient is the sixth reported male subject affected by both disorders. This might suggest that the large female preponderance of 10:1 seen in primary biliary cirrhosis (1) may be offset in the presence of gluten-sensitive enteropathy.

It is well recognized that both primary biliary cirrhosis and celiac disease may be relatively asymptomatic for extended periods of time. Indeed, a recent Scandinavian study suggests that about $50 \%$ of patients with adult celiac disease have no gastrointestinal symptoms (19). In primary biliary cirrhosis the prevalence of asymptomatic patients ranges from 13 to $48 \%$ (20). However, most of the reported cases in which both diseases coexisted were symptomatic, with weight loss, diarrhea and dermatitis herpetiformis most frequently reported (7-18).

The present patient was somewhat unusual in that he was virtually asymp. tomatic. Subclinical steatorrhea might have been present, as quantitative stool fat determinations were not performed. Although the patient had no specific complaints prior to treatment, he noticed an improved sense of well. being after starting a gluten-free diet, a phenomenon frequently seen in treated celiacs (21).

The present patient's serum alkaline phosphatase decreased from $1195 \mathrm{U} / \mathrm{L}$ prior to treatment to 762 , after he was on a gluten-free diet for slightly more than two years, while his aspartate aminotransferase level did not improve significantly. It is difficult to know whether this reflects an improvement in his liver disease, and a repeat liver biopsy would not necessarily be able to settle this issue because of the possibility of sampling error. Alternatively, improvement of an associated subclinical metabolic bone disease could have been reflected in a drop in serum alkaline phosphatase.

In none of the previously reported cases was there significant improvement of primary biliary cirrhosis after treatment with a gluten-free diet. Similarly, primary sclerosing cholangitis does not appear to be affected by dietary 
treatment in the three recently reported patients with celiac disease (5). However, other types of liver injury in celiac patients may be reversible, and progressive liver disease may be preventable by a gluten-free diet in such patients (2).

There appears to be no obvious reason for the association between primary biliary cirrhosis and celiac disease. Jliffe and Owen (9) estimated the likelihood of both diseases occurring in the same patient to be on the order of one in 90 million; a chance association thus seems improbable.

Several theories have been put forward to explain a common etiology between the two diseases (14). A genetic predisposition appears unlikely, as the close association between celiac disease and the HLA loci B8 and DR3, seen in the present patient, is not shared with

\section{REFERENCES}

1. Vierling JM. Primary biliary cirrhosis. In: Zakim D, Boyer TD, eds. Hepatology: A Textbook of Liver Disease. Philadelphia: WB Saunders, 1990:1158-205.

2. Hagender B, Brandt L, Sjölund K, Berg NO, Norden A, Stenstam M. Hepatic iniury in adult coeliac disease. Lancet 1977;ii:270-2.

3. Naschitz JE, Yeshurun D, Zuckerman E, Arad E, Boss JH. Massive hepatic steatosis complicating adult celiac disease - Report of a case and review of the literature. Am J Gastroenterol 1987;82:1186-9.

4. Lindberg J, Ahren C, Jonsson J. Gluten-free diet in chronic active hepatitis associated with intestinal villous atrophy. Hepatogastroenterology 1982;29:52-4.

5. Hay JE, Wiesner RH, Shorter RG, LaRusso NF, Baldus WP. Primary sclerosing cholangitis and celiac disease: A novel association. Ann Intern Med 1988;109:713-7.

6. Schaffner F, Bach N. Gastrointestinal syndromes in primary biliary cirrhosis. Semin Liver Dis 1988;8:263-71.

7. Lee FI, Murray SM, Norfolk D, Vasudev KS. Primary biliary cirrhosis and coeliac disease. Lancet 1978;i:713.

8. Craxi A, Pinzello G, Oliva L, Pagliaro primary biliary cirrhosis (20). Circulating immune complexes derived from the abnormal gut mucosa could conceivably be deposited in portal tracts in the liver and thus play a direct role in tissue injury (7). This is also a proposed mechanism for other autoimmune disorders associated with celiac disease (22). Circulating immune complexes are found in some patients with primary biliary cirrhosis, but their role in the pathogenesis of the liver disease remains unclear, and current data suggest that it is unlikely that immune complexes play a significant role in primary biliary cirrhosis (20).

A common defect in the cellular immune response may be a possible etiological link between celiac disease and primary biliary cirrhosis. Hence, in celiac disease abnormal suppressor

L. Primary biliary cirrhosis and coeliac disease. Lancet 1978;i:713-4.

9. Jliffe GD, Owen DA. An association berween primary biliary cirrhosis and jejunal villous atrophy resembling celiac disease. Dig Dis Sci 1979;24:802-6.

10. Logan RF, Ferguson A, Finlayson ND, Weir DG. Primary biliary cirrhosis and coeliac disease - An association? Lancet 1978;i:230-3.

11. Shanahan F, Crowe JP, O'Regan PF. Primary biliary cirrhosis associated with coeliac disease. Ir Med ] 1983;76:282.

12. Schrijver G, Van Berge Henegouwen GP, Bronkhorst FB. Gluten-sensitive coeliac disease and primary biliary cirrhosis syndrome. Neth ] Med 1984;27:218-21.

13. Fagan EA, Moore-Gillon JC, Turner-Warwick M. Multiorgan granulomas and mitochondrial antibodies. N Engl I Med 1983;308:572-5.

14. Behr W, Barnert J. Adult celiac disease and primary biliary cirrhosis. Am J Gastroenterol 1986;81:796-9.

15. Gabrielsen TO, Hoel PS. Primary biliary cirrhosis associated with coeliac disease and dermat it is herpetiformis. Dermatologica 1985;170:31-4.

16. Olsson R, Kagevi I, Rydberg L. On the concurrence of primary biliary cirrhosis
T cell function may permit cytotoxic reactions directed against enterocytes to which gluten is bound (23). Diminished $T$ suppressor cell function has also been shown to occur in primary biliary cirrhosis, and this may play a part in the autoimmune process, allowing, for example, cytotoxic T lymphocyte responses against native cholangiocyte antigens or neoantigens (23).

Irrespective of the underlying pathogenetic mechanism, it is important for the clinician to be aware of the possible coexistence of both disorders, which may even be asymptomatic in the early stages, as was the case in the patient presently described. Biochemical hepatic evaluation should be included in the work-up of patients suffering from celiac disease.

and intestinal villous atrophy. Scand J Gastroenterol 1982;17:625-8.

17. Löfgren J, Järnerot $G$, Danielsson D, Hemdal I. Incidence and prevalence of primary biliary cirrhosis in a defined population in Sweden. Scand J Gastroenterol 1985;20:647-50.

18. Walton C, Walton S. Primary biliary cirrhosis in a diabetic male with dermatitis herpetiformis. Clin Exp Dermatol 1987;12:46-7.

19. Midhagen $G$, Järnerot $G, K$ raaz W. Adult coeliac disease within a defined geographic area in Sweden. A study of prevalence and associated diseases. Scand J Gastroenterol 1988;23:1000-4.

20. Kaplan MM. Primary biliary cirrhosis. N Engl J Med 1987;316:521-8.

21. Trier JS. Celiac sprue. In: Sleisenger $\mathrm{MH}$, Fordtran JS, eds. Gastrointestinal Disease - Pathophysiology, Diagnosis, Management, 4 th edn. Philadelphia: WB Saunders, 1989:1134-52.

22. Scott BB, Losowsky MS. Coeliac disease: A cause of various associated diseases. Lancet 1975;i:956-7.

23. Falchuk ZM. Gluten-sensitive enteropathy. Clin Gastroenterol 1983; 12:475-94.

24. James SP, Hoofnagle JH, Strober W, Jones EA. Primary biliary cirrhosis: A model autoimmune disease. Ann Intern Med 1983;99:500-12. 


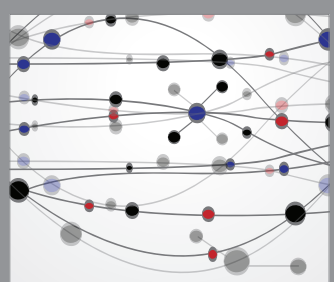

The Scientific World Journal
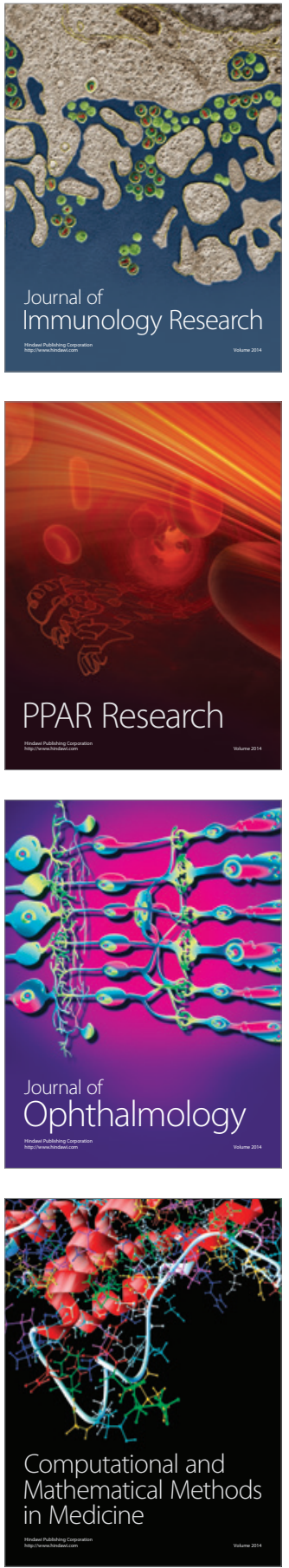

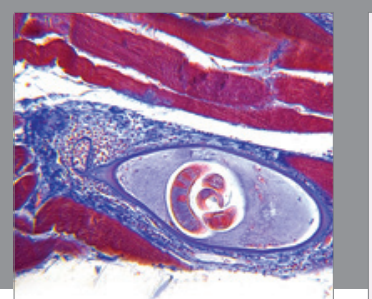

Gastroenterology Research and Practice

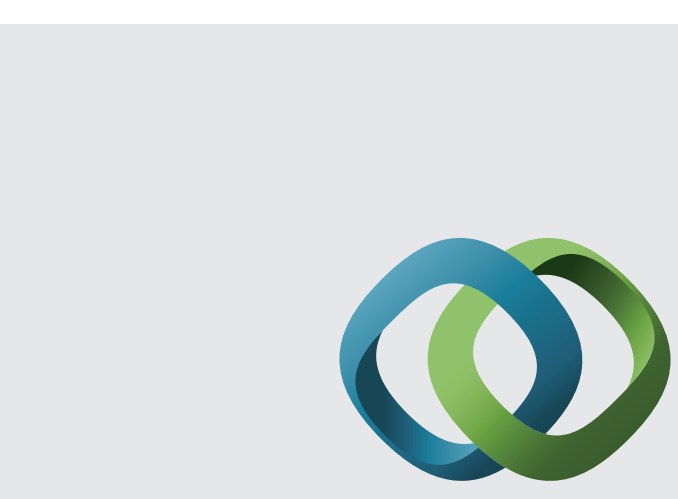

\section{Hindawi}

Submit your manuscripts at

http://www.hindawi.com
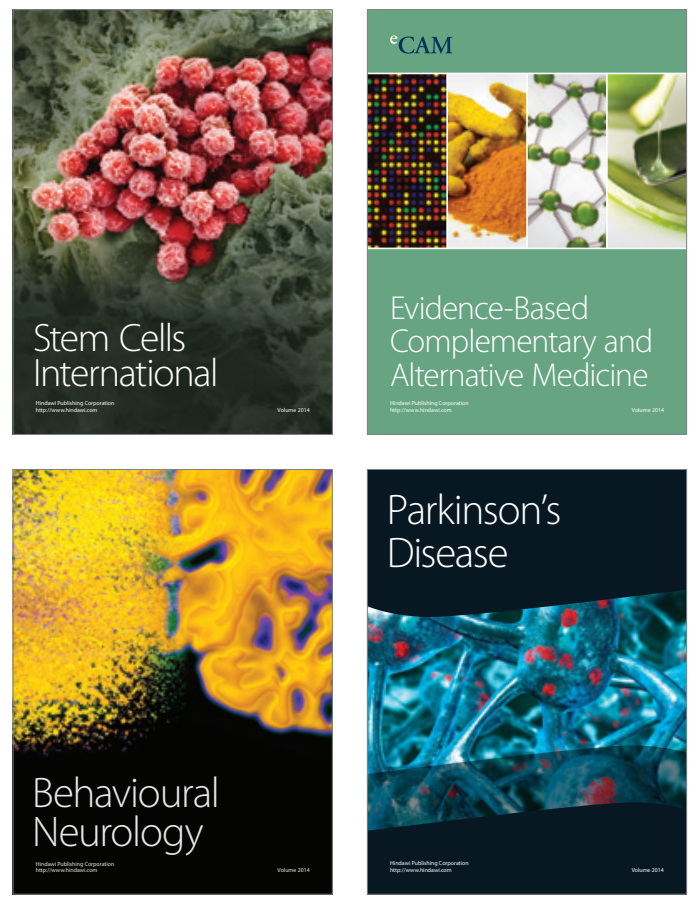
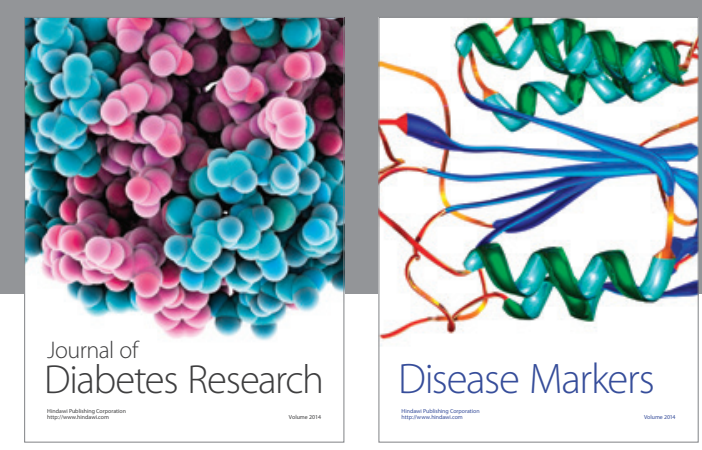

Disease Markers
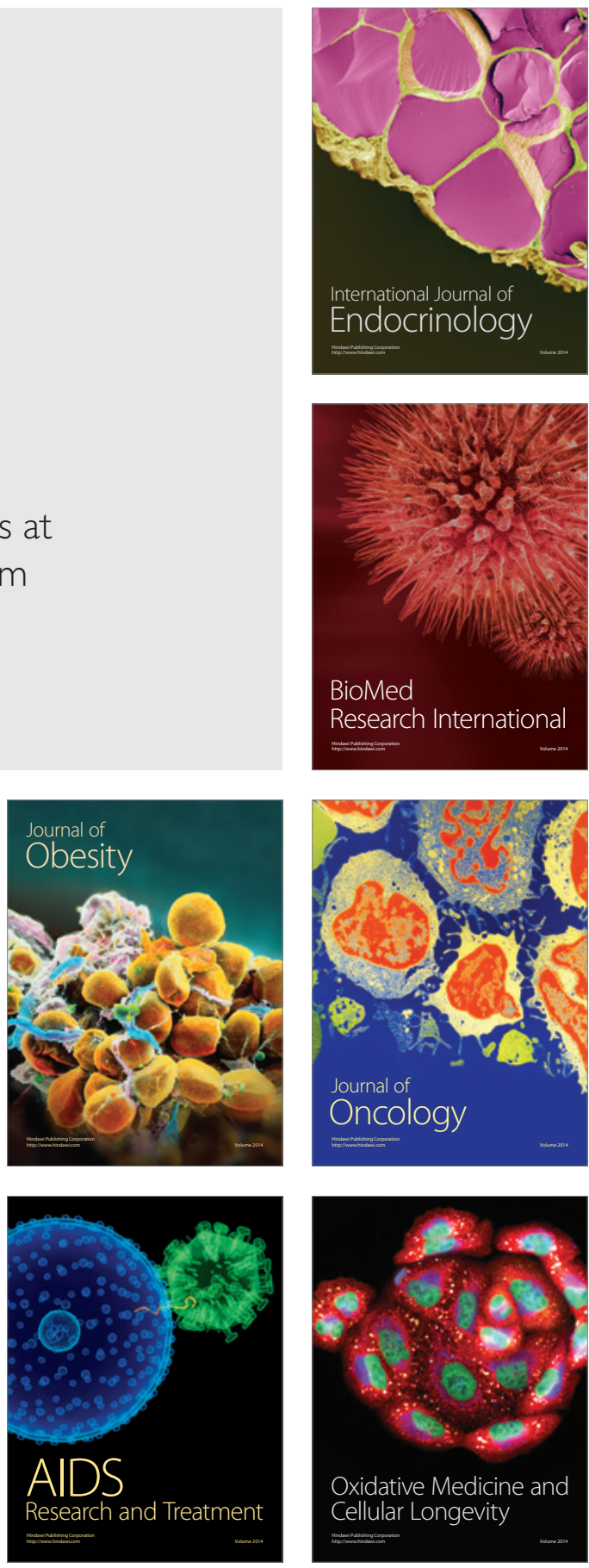